\title{
Observations of the 2004 and 2006 Indian Ocean tsunamis from a pressure gauge array in Indonesia
}

\author{
Kyla Drushka, ${ }^{1}$ Janet Sprintall, ${ }^{1}$ Sarah T. Gille, ${ }^{2}$ and Widodo S. Pranowo ${ }^{3,4}$
}

Received 26 November 2007; revised 15 April 2008; accepted 5 May 2008; published 25 July 2008.

[1] Five shallow pressure gauges located in straits in the southern Indonesian islands were used to evaluate tsunami signals triggered by the earthquakes off the northwest coast of Sumatra in December 2004 and the south coast of Java in July 2006. Tsunami waves reached the pressure gauges around 5 to 6 hours after the 2004 earthquake; the largest waves arrived 10 to 23 hours later, with amplitudes ranging from 9 to $25 \mathrm{~cm}$. After the 2006 earthquake, tsunami arrivals were only evident at the Ashmore and Roti pressure gauges in Timor Passage. At these two gauges, the first waves arrived around 2.25 hours after the earthquake, and the largest waves arrived 2 to 3 hours later, with amplitudes of 6 and $18 \mathrm{~cm}$. Spectral analysis shows an increase of energy in the 40- to 80-min-period band during the 2004 tsunami, and at periods of 10 to $20 \mathrm{~min}$ in 2006. A simple ray tracing model of both the 2004 and 2006 events, which approximates the tsunami as a shallow water wave, was used to evaluate the effect of topography on tsunami propagation in order to provide a physical explanation for the features observed in the pressure gauge data.

Citation: Drushka, K., J. Sprintall, S. T. Gille, and W. S. Pranowo (2008), Observations of the 2004 and 2006 Indian Ocean tsunamis from a pressure gauge array in Indonesia, J. Geophys. Res., 113, C07038, doi:10.1029/2007JC004662.

\section{Introduction}

[2] On 26 December 2004 at 0059 UTC, a magnitude $\mathrm{M}_{W}$ 9.3 earthquake off the west coast of Sumatra (Figure 1) generated a tsunami that devastated coastal communities around the Indian Ocean [Stein and Okal, 2005]. On 17 July 2006 at 0819 UTC another, less destructive $\left(\mathrm{M}_{W} 7.7\right)$, earthquake occurred about $200 \mathrm{~km}$ off the south coast of the Indonesian island of Java [Fujii and Satake, 2006; Lavigne et al., 2007]. The 2004 and 2006 earthquakes differed in magnitude, location and source orientation, as well as in the destruction they caused. Here, data from a shallow pressure gauge array in the Indonesian islands are used to compare the tsunami properties during the two events. We evaluate the effect that the complicated bathymetry of the Indonesian archipelago had on the tsunami propagation and the associated wave height, which may help in building an effective tsunami warning system for this region.

[3] Observational and modeling studies have shown that most of the 2004 Sumatra tsunami energy traveled to the

\footnotetext{
${ }^{1}$ Scripps Institution of Oceanography, University of California, San Diego, La Jolla, California, USA.

${ }^{2}$ Scripps Institution of Oceanography and Department of Mechanical and Aerospace Engineering, University of California, San Diego, La Jolla, California, USA

${ }^{3}$ Research Center for Maritime Territories and Non-living Resources, Agency for Marine and Fisheries Research, Ministry of Marine Affairs and Fisheries, Jakarta, Indonesia.

${ }^{4}$ Now at Alfred Wegener Institute for Polar and Marine Research, Bremerhaven, Germany.
}

Copyright 2008 by the American Geophysical Union. 0148-0227/08/2007JC004662\$09.00 west from the earthquake source region [e.g., Kowalik et al., 2005; Merrifield et al., 2005; Nagarajan et al., 2006; Rabinovich and Thomson, 2007]. Rabinovich and Thomson [2007] presented records from 45 tide gauges in the Indian Ocean and showed that tsunami amplitudes at stations west of the earthquake epicenter were generally larger than at stations to the east. To the east of the tsunami source region, where our pressure gauge array was located, there were few tide gauges in place and the signal there has not been well documented. Furthermore, many of the tide gauges that recorded the tsunami were located on isolated islands or at other open ocean sites, and thus the signals that they recorded are not necessarily representative of the tsunami magnitude and arrival times within the highly populated Indonesian islands.

[4] The 2004 Sumatra tsunami was modeled by the West Coast/Alaska Tsunami Warning Center (WC/ATWC) [Kowalik et al., 2005]. Results from this model are in agreement with the observations of Rabinovich and Thomson [2007], showing primarily westward energy propagation and a relatively weak signal propagating eastward along the south coast of Sumatra and Java (see Figure 1). In the Java Sea region, where the average depth is less than $100 \mathrm{~m}$ and numerous islands and passages complicate the bathymetry, the tsunami arrival patterns of the WC/ATWC model are extremely convoluted [see Merrifield et al., 2005, Figure 5]. Because tsunami propagation models rely heavily on accurate bathymetry, they are not guaranteed to perform well where bathymetry is complicated.

[5] Following the 2006 earthquake, Lavigne et al. [2007] measured tsunami runup heights along the south coast of Java. Their results suggest that the tsunami waves propa- 


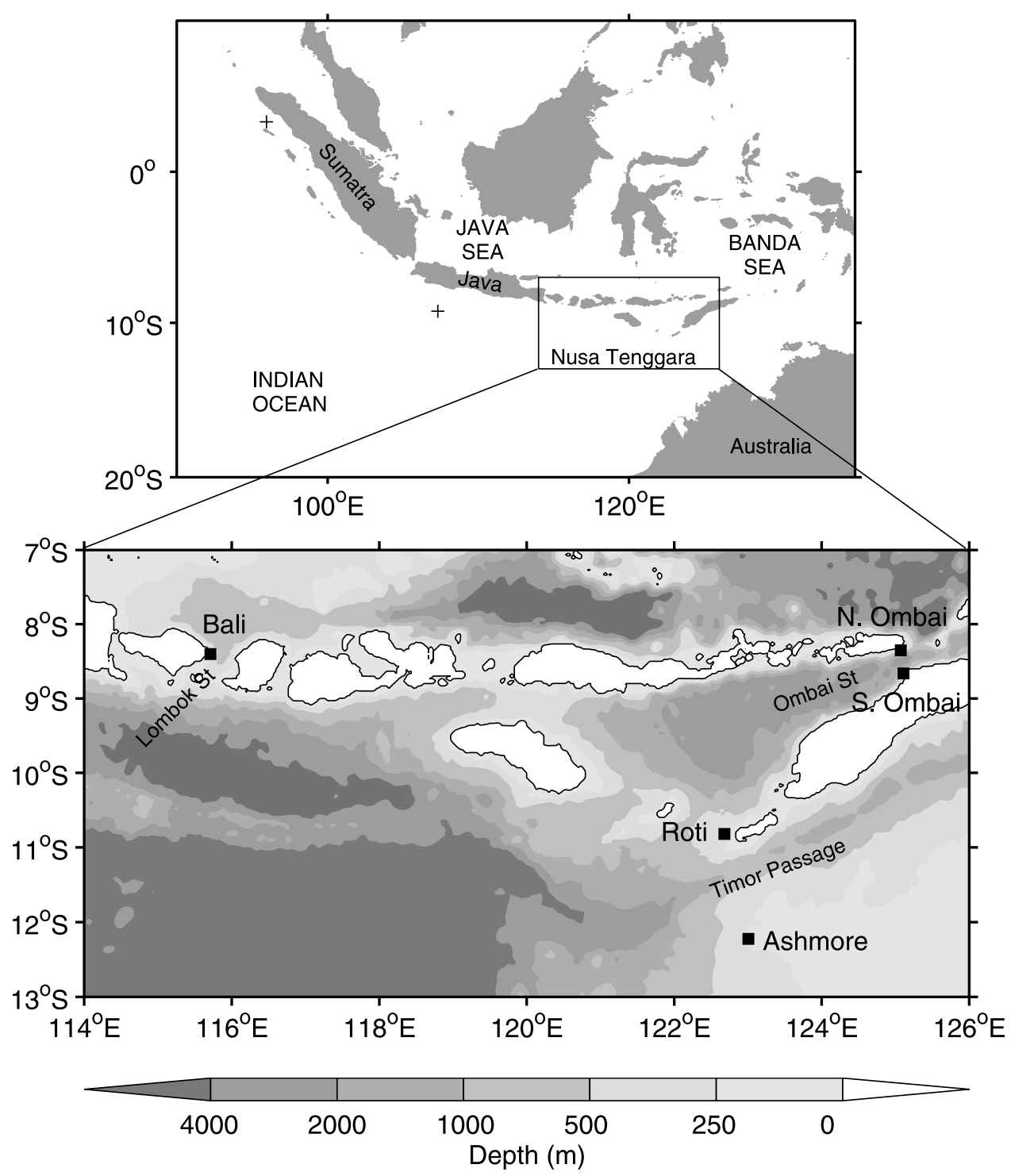

Figure 1. Study region. (top) Locations of earthquake epicenters are indicated by plus signs west of North Sumatra (December 2004 earthquake) and south of Java (July 2006 earthquake). (bottom) The pressure gauge locations are indicated by squares. Bathymetric contours are in meters.

gated eastward from the source region, and that local topography played a large role in determining the local magnitude of the waves. A World Health Organization report tells the same story: most of the damage was confined to central Java, with no casualties west of the earthquake epicenter (http://www.searo.who.int/LinkFiles/Indonesia__Emergency_Situation_Report_ESR_11_3_Aug-06.pdf).

[6] In this paper we present data from five shallow pressure gauges that were located in the southern Indonesian island chain of Nusa Tenggara (Java east to Timor) during both the 2004 and 2006 tsunamis. The instruments were situated in narrow straits of varying sill depths, so the tsunami arrivals to the gauges were complicated by effects of bathymetry. The Indonesian archipelago has an enormous population density, mostly in coastal communities vulnerable to the effects of a large tsunami. Although tsunamis are relatively common in the region, their propagation through the thousands of islands and bathymetric features is too complex to model well and it is therefore difficult to put an effective tsunami warning system in place. The objective of this study is to use the data from pressure gauges located within the Indonesian islands during two distinct tsunami events in order to observe the propagation of high-frequency wave energy through the Indonesian archipelago. The paper is organized as follows: the pressure gauge data set is described in section 2 and the time series during the tsunamis presented in section 3; spectral analyses of the pressure data are given in section 4; section 5 contains results from a ray tracing model of the two events; finally, the results are discussed in section 6 .

\section{Data}

[7] The tsunami signals were measured by shallow pressure gauges deployed as part of the International Nusantara STratification ANd Transport (INSTANT) program. INSTANT was a 3-year field program primarily designed to measure the long-term heat and freshwater flux 
a

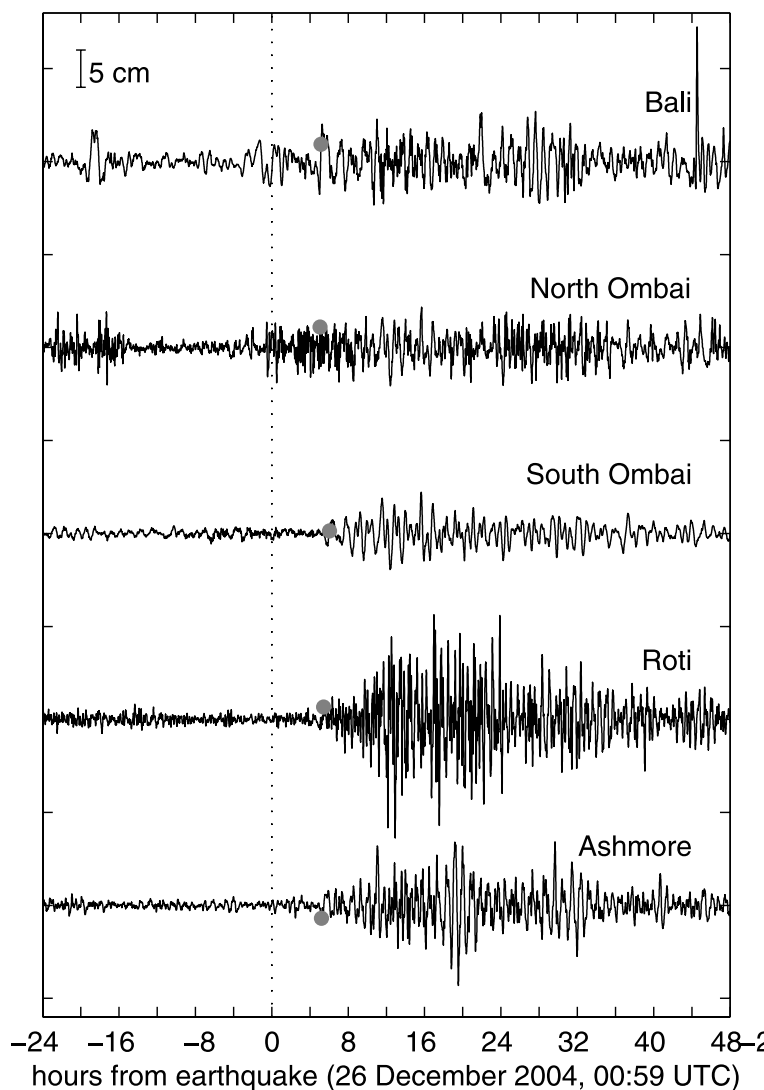

b

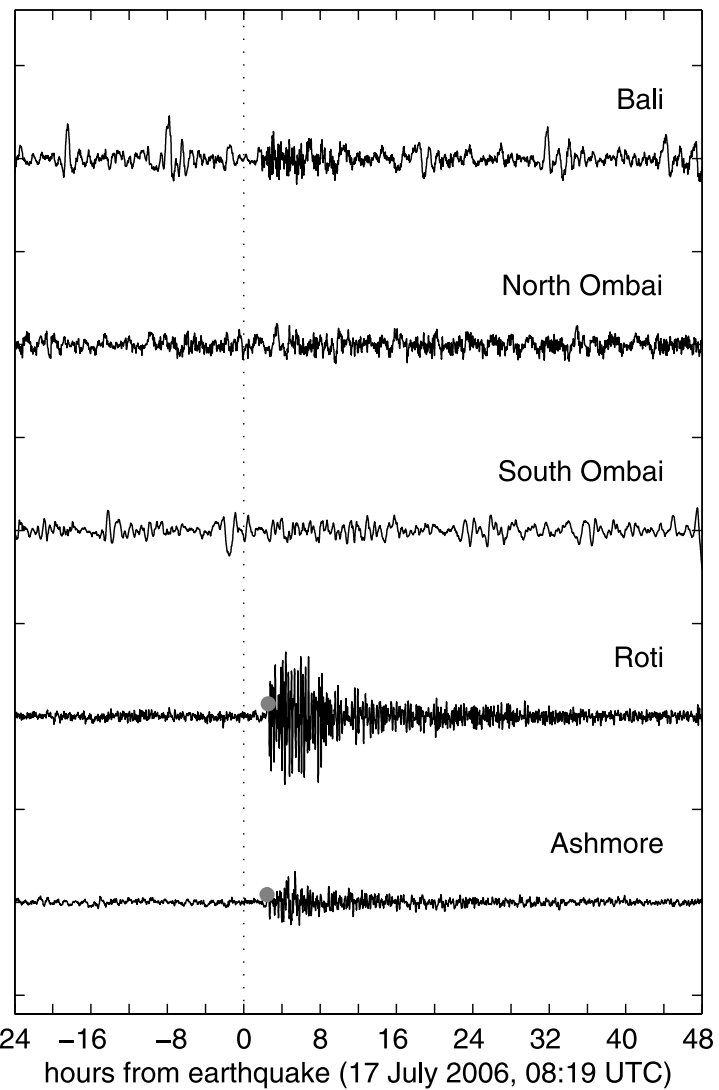

Figure 2. Detided pressure data, from one day prior and two days following the earthquake (indicated by the dotted line), for the (a) 2004 Sumatra and (b) 2006 Java earthquakes. Tsunami arrival times, where they could be calculated, are plotted as grey dots. For clarity, the data have been low-pass filtered with a cutoff frequency of $10 \mathrm{cph}$.

in the Indonesian Throughflow (ITF). The INSTANT array consisted of eleven deep moorings in the major inflow and outflow passages of the ITF, as well as shallow coastal pressure gauges deployed on either side of Timor, Ombai and Lombok outflow passages [Sprintall et al., 2004]. The pressure gauges were positioned on either side of these straits to best capture pressure differences across the straits in order to make proxy measurements of geostrophic flow, so it was fortuitous timing that the instruments were deployed during the two tsunami events.

[8] Five pressure gauges were in operation during the tsunamis: these were located off of Bali (Lombok Strait), North Ombai and South Ombai (Ombai Strait), Ashmore Reef and Roti (Timor Passage), as shown in Figure 1. The Bali, North Ombai and Roti gauges were deployed in January 2004, and the South Ombai and Ashmore gauges were deployed in August 2003. The Bali, Roti, and North and South Ombai gauges collected data until June 2005, and the Ashmore gauge was retrieved in March 2007. A sixth gauge, on Lombok Island on the eastern side of Lombok Strait, was in place from January 2004 but failed in October 2004 and hence did not capture the tsunami events. The gauges were deployed $\sim 20$ to $40 \mathrm{~m}$ off the coast of each island in 5 to $10 \mathrm{~m}$ water depth. Pressure was recorded every $10 \mathrm{~s}$ with $0.3 \mathrm{~cm}(0.3$ mbar $)$ accuracy using Paroscientific pressure sensors. In contrast, tide gauges used in earlier tsunami studies generally had temporal sampling of several minutes to an hour and were an order of magnitude less accurate [Rabinovich and Thomson, 2007]. Pressure gauges are able to measure tsunami waves of much smaller magnitudes than those that can be detected with tide gauges [Baba et al., 2004].

[9] Tides are the largest sea level signal in the pressure gauge records from these narrow passages: on average, the tidal component of the pressure gauge signal was order $1 \mathrm{~m}$ and the tsunami signal was order $10 \mathrm{~cm}$. Removing the tidal signal from the data was an important and nontrivial step required to isolate the smaller tsunami signal from the data. We compared two methods of detiding the data: the T_tide program of Pawlowicz et al. [2002] fits sinusoids of the dominant tidal frequencies in a least squares sense to construct a tidal signal that can then be subtracted from the data; the method of Thompson [1983] uses low-pass filters to suppress inertial and tidal frequencies. Using these methods to detide 6-month or greater segments of the $10 \mathrm{~s}$ pressure data yielded almost identical results. The Pawlowicz et al. [2002] program was less computationally expensive when processing long time series, and was thus used for the analysis presented here. A Hamming filter was used to compute a $60-\mathrm{min}$ running mean, which was subtracted from the detided data to remove a periodic signal that the detiding schemes could not capture. We explored running 
Table 1. Tsunami Observations and Model Results at Pressure Gauge Sites ${ }^{\text {a }}$

\begin{tabular}{|c|c|c|c|c|c|c|c|c|c|}
\hline \multirow[b]{2}{*}{ Station } & \multicolumn{4}{|c|}{2004 Sumatra Tsunami } & \multicolumn{5}{|c|}{2006 Java Tsunami } \\
\hline & Traveltime & Peak Time & $\begin{array}{c}\text { Peak } \\
\text { Amplitude } \\
(\mathrm{cm})\end{array}$ & $\begin{array}{l}\text { Max Energy } \\
\text { Period (min) }\end{array}$ & Traveltime & Peak Time & $\begin{array}{c}\text { Peak } \\
\text { Amplitude } \\
(\mathrm{cm})\end{array}$ & $\begin{array}{l}\text { Max Energy } \\
\text { Period (min) }\end{array}$ & $\begin{array}{l}\text { Ray Trace } \\
\text { Traveltime }\end{array}$ \\
\hline Bali & $4: 58$ & $28: 03$ & 12.3 & 51 & - & $32: 09$ & 6.3 & 12 & $1: 13 \pm: 03$ \\
\hline North Ombai & $4: 51$ & $24: 35$ & 9.8 & 80 & - & $9: 56$ & 4.7 & 6 & $3: 13 \pm: 04$ \\
\hline South Ombai & $5: 51$ & $15: 56$ & 9.3 & 80 & - & $25: 54$ & 4.2 & 15 & $3: 13 \pm: 04$ \\
\hline Roti & $5: 13$ & $16: 59$ & 24.6 & 40 & $2: 22$ & $4: 24$ & 17.7 & 18 & $2: 10 \pm: 06$ \\
\hline Ashmore & $5: 00$ & $19: 33$ & 19.3 & 51 & $2: 14$ & $5: 35$ & 5.9 & 15 & $2: 14 \pm: 06$ \\
\hline
\end{tabular}

${ }^{a}$ Traveltimes are in hours:minutes since the earthquake, with blank values indicating that the data were too noisy to determine an accurate traveltime. Peak time is the traveltime for the largest wave observed; peak amplitude is the trough-to-crest amplitude of this wave (Figure 2). Max energy period is the period corresponding to the maximum tsunami energy greater than the background level (Figure 3). Ray trace traveltime was calculated using the ray tracing model \pm the standard deviation computed using 25 point sources for the rays; this column is omitted for the Sumatra event because no rays could be traced to within one degree of any pressure gauge site (Figure 5).

mean window sizes ranging from 30 to 120 min and found that the choice did not significantly affect the results.

\section{Time Series Data}

[10] Figure 2 shows the pressure anomaly observed at each of the five gauges one day before and two days following the 2004 and 2006 earthquakes. Although the data have been detided, background fluctuations in pressure are large at some stations, and signal-to-noise ratios can be low. This is especially the case at Bali and North Ombai during both tsunami events (Figure 2), as well as at South Ombai for the 2006 event (Figure 2b): compared to the relatively exposed Roti and Ashmore stations, these gauges were sheltered from the incoming waves generated by the earthquakes, and the tsunami signals are buried in the background noise. To determine the tsunami traveltimes (Table 1), a background level of variance at each station was computed from the 24 hours of data before the earthquake. Then, a 25-min running variance of each detided and low-pass-filtered time series was computed. The traveltime was calculated as the difference between the time of the earthquake and the first time that the standard deviation of the time series exceeded 1.5 standard deviations of the background signal.

[11] During the 2004 event, the tsunami waves arrived at the Nusa Tenggara stations during the ebb tide, around five to six hours after the earthquake (Table 1). Rabinovich and Thomson [2007] note that at tide gauges near the tsunami source region, the largest wave was generally the first to arrive, and farther afield the largest wave arrived later. At the Nusa Tenggara stations, however, the largest waves arrived 10 to 23 hours after the first waves (Table 1), in spite of the pressure gauges' near proximity to the earthquake epicenter. The more sheltered gauges at Bali and North and South Ombai registered maximum trough-tocrest amplitudes of 9 to $12 \mathrm{~cm}$, compared to $19.3 \mathrm{~cm}$ at Ashmore and $24.6 \mathrm{~cm}$ at Roti (Table 1). This is consistent with Indonesian tide gauge data shown by Rabinovich and Thomson [2007], as well as with the peak at Nusa Tenggara seen in the WC/ATWC model results [Kowalik et al., 2005] that arrives around 12 hours following the earthquake after appearing to reflect off of Sri Lanka. The tsunami signals east of the source region were sufficiently small that they could not be distinguished from noise in satellite altimeter data (not shown), in contrast to signals near the source that were clearly visible in altimeter measurements [Gower,
2005; Smith et al., 2005; Hayashi, 2008]. Thus using the altimeter measurements we were unable to identify open ocean propagation of the tsunami toward the Indonesian archipelago.

[12] After the 2006 earthquake, only the Roti and Ashmore pressure gauges measured a significant tsunami signal (Figure 2b). The largest wave at Roti arrived two hours after the first wave; the much smaller peak wave seen at Ashmore arrived over 3 hours after the first (Table 1). The signal-to-noise ratios are too low to clearly distinguish the tsunami signal at the other stations. At Bali, the closest site to the epicenter of the 2006 earthquake, the tsunami signal appears visible by eye in the time series but the arrival is not distinguishable according to the statistical criteria described above. As during the 2004 tsunami event, no trace of the 2006 tsunami could be detected in satellite altimetry measurements near Nusa Tenggara.

[13] There are differences in the signals at North and South Ombai during both the 2004 and the 2006 events, noteworthy because the stations are close together. In the 2004 event, the background is noisier at North Ombai and the tsunami signal is ambiguous in comparison to that at South Ombai (Figure 2a). In 2006, tsunami signals are not readily apparent at either gauge, but there are generally more high-frequency fluctuations at North Ombai (Figure 2b). Ombai Strait, $35 \mathrm{~km}$ wide and $2700 \mathrm{~m}$ deep between the gauges, is a major outflow passage for the ITF [Chong et al., 2000; Potemra et al., 2003]. The south side of the strait is steeply sloped in comparison to the north side, which has a shallow shelf running several kilometers offshore [see Molcard et al., 2001, Figure 3]. Moorings deployed on either side of Ombai Strait as part of INSTANT show that the main ITF is strongly trapped to the southern side of the strait (not shown). The discrepancy between the two pressure gauges during the tsunamis is likely due in part to a combination of ITF dynamics and topographic effects.

\section{Spectral Energy}

[14] Figure 3 shows comparisons of spectral energy at each station before and during the 2004 and 2006 tsunamis. The background spectra were formed from the seven days of data before the tsunami $(60,480$ data points) and the tsunami spectra were computed from the two days following the first wave arrival (17,280 data points). A 12-hour Kaiser-Bessel window with $50 \%$ overlap was used, giving 54 and 14 degree-of-freedom spectral estimates for the 


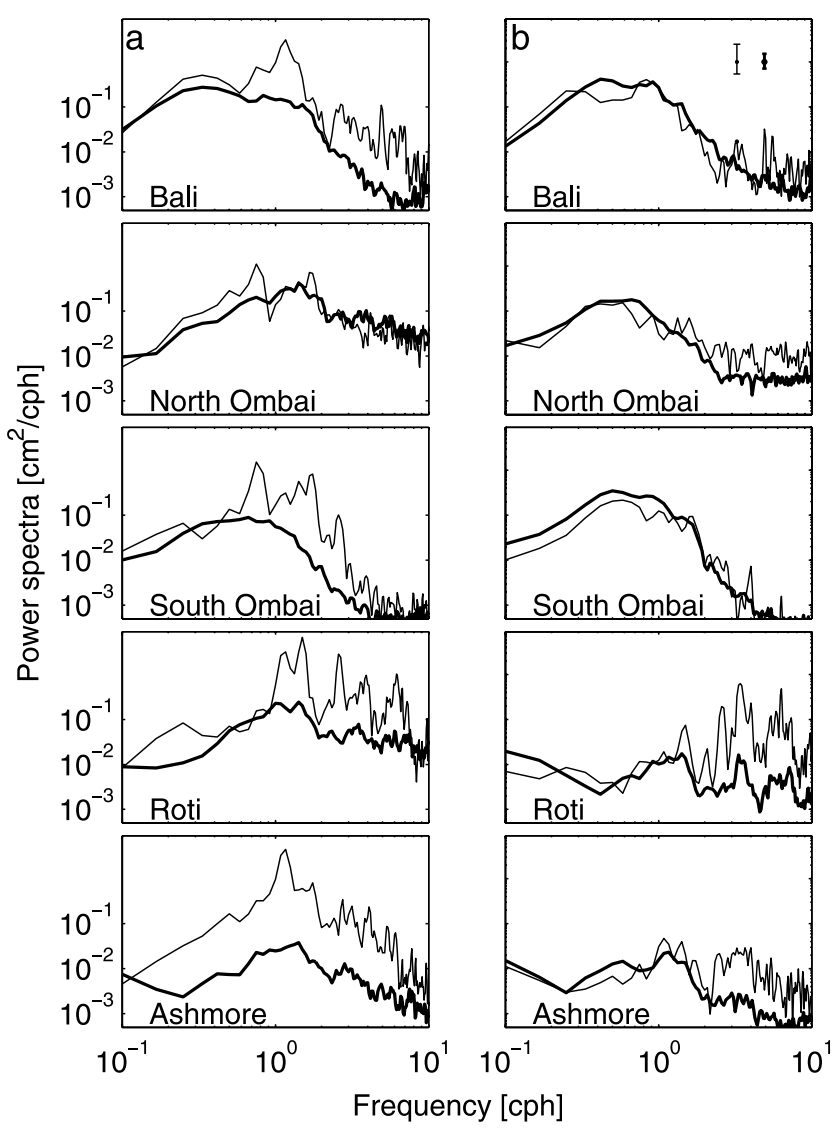

Figure 3. Power spectra of pressure data comparing spectral energy for the 7 days before (thick line) and 2 days following (thin line) the (a) 2004 Sumatra and (b) 2006 Java earthquakes. The magnitudes of the uncertainties are indicated in the upper right.

background and tsunami data, respectively. For the 2004 event (Figure 3a), the tsunami energy at every location is significantly higher at low frequencies than the pre-tsunami energy. At high frequencies (not shown) the tsunami energy is similar to, although slightly lower than, the background. The tsunami energy peaks have periods of 40 to $80 \mathrm{~min}$ (Table 1). For the 2006 Java event (Figure 3b), the background and tsunami energy are statistically indistinguishable at all stations except Roti, which has several large tsunami peaks at frequencies higher than $2 \mathrm{cph}$, and Ashmore, which shows consistently high tsunami energy at frequencies higher than $2 \mathrm{cph}$. A comparison of the 2004 and 2006 Roti spectra shows peaks of the same frequencies (e.g., periods of 23 and $40 \mathrm{~min}$ ) with different relative magnitudes for the two events. For both events, the background and tsunami spectra have similar shapes at most stations, suggesting that the tsunami signal is a resonant amplification of the normal background response to the local topography [cf. Van Dorn, 1984]. Because the INSTANT pressure gauges were in open, exposed locations rather than in harbors or semiclosed basins, the spectral peaks in the pressure time series are not a result of basin resonant effects such as what might be seen in the case of tide gauges located in harbors. In this sense, the energy peaks of the pressure data are akin to what could be expected from open ocean tide gauges.
[15] To better understand the shift in energy suggested by the comparisons of spectra, wavelet analysis was applied to the data following Torrence and Compo [1998]. Figure 4 shows the spectrograms ( $f-t$ plots) for 1 day preceding and 2 days following the 2004 and 2006 earthquakes. Station by station, the spectrogram structures are similar in 2004 and 2006, generally showing the same dominant bands of energy. The $f$ - $t$ plots from the 2004 event (Figure 4a) show significant postearthquake energy in the 15- to 120-minperiod band, in agreement with the findings of Rabinovich and Thomson [2007]. In their spectrograms of the 2004 tide gauge data, Rabinovich and Thomson [2007] observed distinctive pulses of energy. They suggest that this "wave train" structure results when energy is pumped into local oscillations by topographic refraction and reflection. This structure can be seen at all sites shown in the $f$ - $t$ plots from the 2004 event (Figure 4a). For example, the wave train pattern at Bali is similar to that of the nearby Lembar station spectra given by Rabinovich and Thomson [2007, Figure 10], showing several distinct trains with the largest waves arriving 28 hours after the earthquake. In contrast, in 2006 the tsunami is not visible in the Bali spectrogram (Figure $4 \mathrm{~b}$ ) and the background energy is on the same order as the tsunami across all frequencies.

[16] After both the 2004 and 2006 earthquakes, Roti and Ashmore stations received the largest tsunami waves. This is evident from the time series data (Figure 2), but can also be seen in the $f$ - $t$ plots (Figure 4). For both events, the Roti spectrogram shows no energy at periods longer than around $60 \mathrm{~min}$, and a strong wave train structure is evident; for the 2006 event, the wave trains are narrower in time and the energy falls off more sharply. The energy at Ashmore is strong in the 30- to 60-min-period band during both events. The 2006 Ashmore spectrogram shows a surge of highfrequency energy induced by the tsunami around 4 to 6 hours after the earthquake.

[17] In both events, the spectral energy at North Ombai is smeared out widely in frequency and in time, including a significant amount of high-frequency energy. In 2006, the background noise at North and South Ombai is considerable (Figure 4b): the energy peak seen at North Ombai just after the earthquake may be a tsunami signal or may be coincidental noise; at South Ombai no trace of the tsunami can be distinguished from the background signal. In 2004, the North Ombai spectrogram (Figure 4a) provides information about the tsunami arrival that the time series (Figure 2a) alone is unable to provide: the spectral energy is smeared out, but the tsunami can be seen as two significant spikes in energy at periods of $35 \mathrm{~min}$ and 70 to $80 \mathrm{~min}$. Although the North and South Ombai time series have substantially different characters, their spectrograms share many features, particularly at the dominant frequencies (periods of $35 \mathrm{~min}$ and 70 to $80 \mathrm{~min}$ ). This suggests that although local topography (e.g., the north versus the south side of Ombai Strait) plays an important role in wave behavior, the properties of the source also have a strong influence on the energy characteristics of the wave [Rabinovich and Thomson, 2007].

\section{Ray Tracing}

[18] To evaluate the effects of topography on tsunami propagation to the pressure gauge sites, we implemented a 


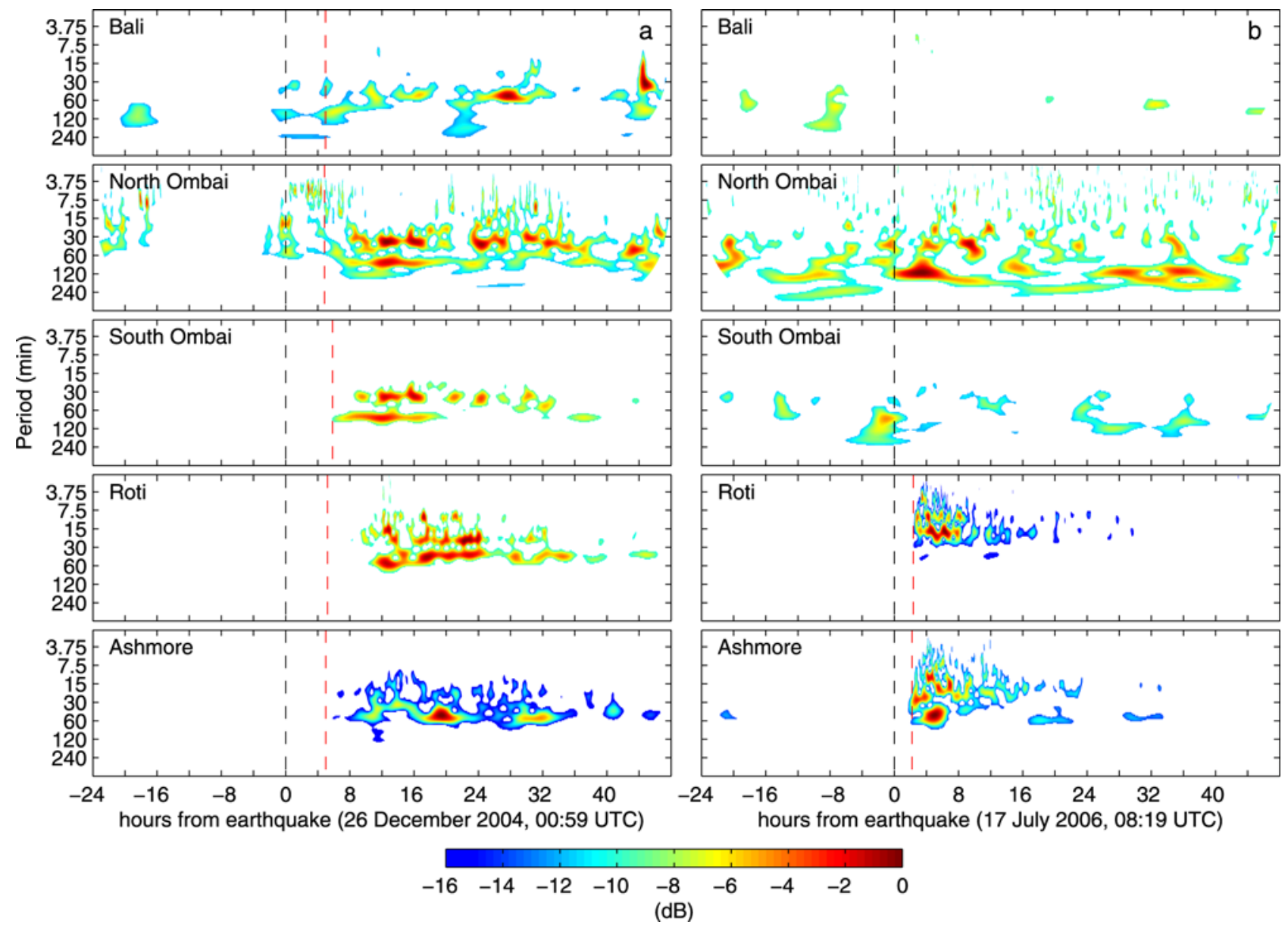

Figure 4. Spectrograms of detided pressure anomaly data for the (a) 2004 Sumatra and (b) 2006 Java earthquakes. The power has been normalized to the maximum power for each plot; areas with less than 95\% significance have been masked out. The earthquake time is indicated with a black dashed line, and the observed arrival time, where available (Table 1), is indicated with a red dashed line.

simple model using the ray tracing equations for seismic surface waves over a sphere [Satake, 1988]. The model used a short wavelength approximation and only included the refractive effects of bathymetry, relying on the 30-arcsecond Smith and Sandwell bathymetric grid (http://topex.ucsd. edu). The resolution of the bathymetry was considered too coarse to incorporate reflection into the model with any confidence. Thus, our model will not identify tsunami signals that arrive at the pressure gauges after one or more reflections off of topography, for example after reflection off of Sri Lanka as suggested by the WC/ATWC model of the 2004 tsunami [Kowalik et al., 2005].

[19] More detailed models, such as that of the $\mathrm{WC} /$ ATWC, are exceptionally useful for a comprehensive look at wave propagation throughout the oceans as well as for predicting the magnitude of tsunami inundation on land. However, complex models can be computationally expensive to run. For example, 40 parallel supercomputer processors required 9 hours to run the WC/ATWC model of the 2004 event. In contrast, the ray tracing model provides a simple, fast, computationally cheap and easy-to-implement tool for making estimates of tsunami traveltime to a specific location. The integration of the ray tracing equations was done easily on a workstation in just a few hours. In the ray tracing model, individual rays were sent outward from a point source in a limited range of directions toward the gauge locations, allowing traveltime estimates to be computed. By sending out rays from numerous point sources located within the tsunami source region, error bars for the traveltime estimates could be determined from the ensembles. We evaluated the accuracy of the ray tracing model by comparing its output to observations [Rabinovich and Thomson, 2007] and WC/ATWC model results from the 2004 Sumatra tsunami at several Indian Ocean tide gauge stations [Kowalik et al., 2005]. The results from comparing the observed and modeled traveltimes show that the ray trace model has the same order of accuracy as the $\mathrm{WC}$ / ATWC model.

[20] Several studies have shown that the source region for the 2004 tsunami stretched over $1000 \mathrm{~km}$ north-northwest of the earthquake epicenter [e.g., Lay et al., 2005; Neetu et al., 2005]. Fine et al. [2005] pinpointed two sources for the tsunami waves: the southern source, around $350 \mathrm{~km}$ northnorthwest of the epicenter, which was responsible for the largest waves; and the northern source, immediately south of the Andaman islands, which was responsible for the smaller waves that hit the northern part of the Bay of Bengal. Figure 5a shows the result of tracing out a fan of 


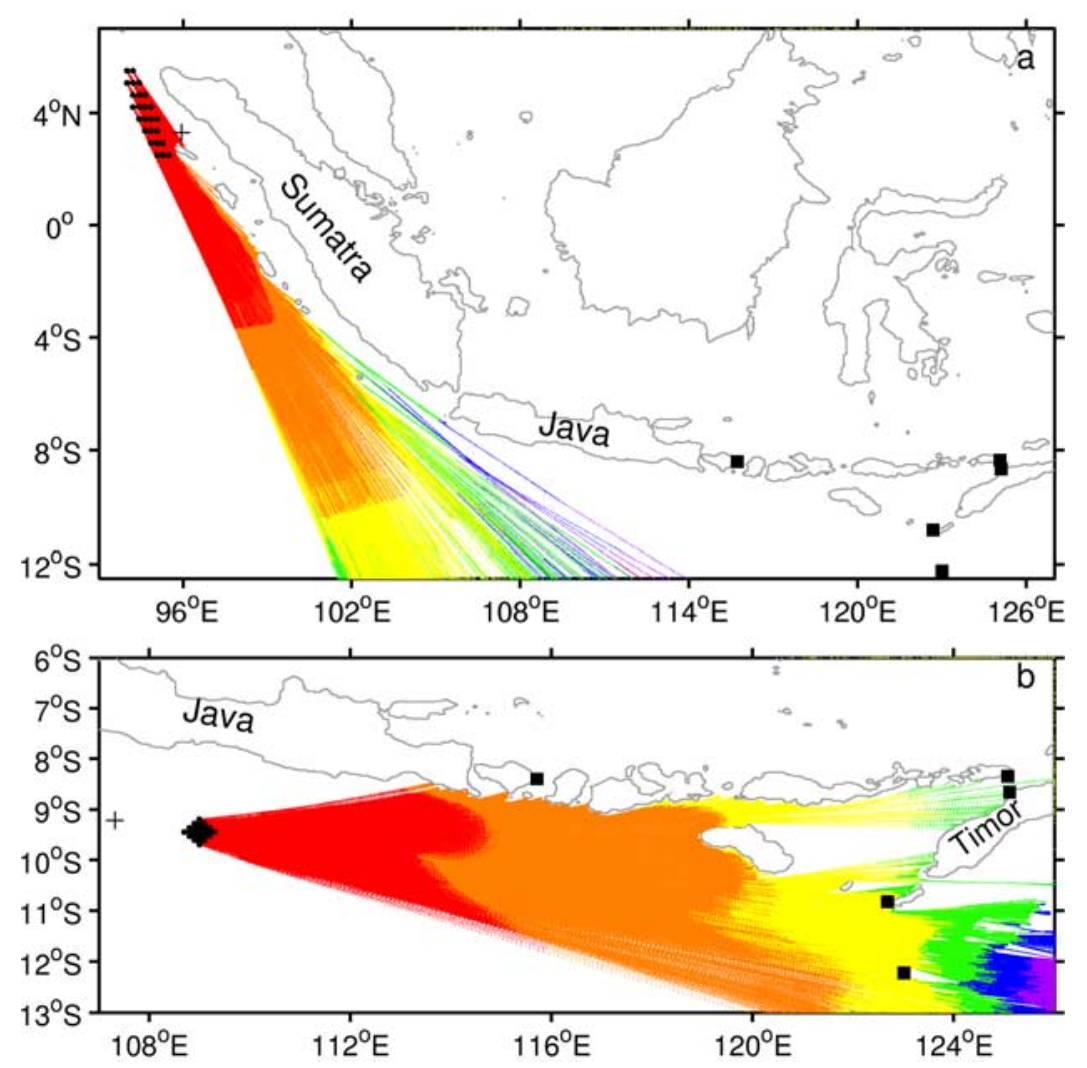

Figure 5. Results of ray trace model for the (a) 2004 Sumatra and (b) 2006 Java earthquakes. Rays were sent out with $0.2^{\circ}$ angular spacing from 25 point sources (indicated by black dots) within the tsunami source region. Each color transition indicates 1 hour of ray traveltime. The earthquake epicenters are shown as plus signs, and the pressure gauge locations are shown as squares. Rays that were sent out in other directions and did not come near to any of the pressure gauge locations have been omitted for clarity.

rays spaced $0.2^{\circ}$ apart, from 25 point origins located within the southern source region of the 2004 tsunami defined by Fine et al. [2005]. Because of the topography of the Indonesian islands, a direct path could not be traced from the source region to any of the pressure gauges. This is consistent with the pressure signals observed at the gauges: the weak signals at Bali and North Ombai (Figure 2a), and the wave trains observed at all stations (Figure 4a) suggest that the waves reached the gauges after one or more reflections. The lack of direct paths between the source region and the exact gauge locations made it impossible to predict traveltimes with any precision using the ray tracing model. We tested the possibility of the peak waves arriving at the Indonesian gauges via reflection off of Sri Lanka by tracing rays westward to the Sri Lankan coast and then southeastward to Indonesia. In this way, the total traveltime obtained by the ray trace model was around 12 to 14 hours, consistent with the times at which the first high-energy signal can be seen on the $f-t$ plots (Figure 4a).

[21] Using the ray tracing technique was more successful for the 2006 Java event, and lent some insight into the differences in signal that were observed between Roti and Ashmore and the other gauges. Figure $5 \mathrm{~b}$ shows the results of tracing rays outward from 25 points within the source region of the 2006 tsunami as defined by Fujii and Satake [2006], again with $0.2^{\circ}$ angular spacing. Numerous rays could be traced directly from the source to the Roti and
Ashmore gauge locations: the modeled traveltime to Ashmore is the same as the observed traveltime, and to Roti the modeled traveltime is within two standard deviations of the observed time (Table 1). Owing to topographical refraction, few rays were able to enter Ombai Strait. The bathymetry did not permit any rays to reach the Bali gauge; the predicted traveltime shown for Bali in Table 1 is for the ray that made it the closest to that gauge (Figure $5 \mathrm{~b}$ ).

[22] To evaluate the sensitivity of the ray tracing algorithm to the choice of bathymetry product, we repeated the simulations using the 1-min gridded General Bathymetric Chart of the Oceans (GEBCO) Digital Atlas published by the British Oceanographic Data Centre. Marks and Smith [2006] compared the GEBCO grid to an older version of the Smith and Sandwell seafloor topography with 2-min grid spacing [Smith and Sandwell, 1997], and concluded that the Smith and Sandwell product generally resolves details better at the small spatial scales that are relevant for the ray tracing application. The 30-arcsecond Smith and Sandwell grid used in this study is an improvement over the 2-min Smith and Sandwell grid discussed by Marks and Smith [2006] and can thus be presumed to perform even better than the 1min GEBCO map (J. Becker, personal communication, 2008). The ray tracing model obtained qualitatively similar results with both bathymetry fields: in neither case did any rays reach the INSTANT gauge locations from the 2004 Sumatra tsunami source region, and the patterns of rays 
from the simulation of the 2006 Java event were similar. This confirms that even 30 -arcsecond bathymetry is too coarse to accurately model the tsunami propagation through a region with such shallow and varied seafloor topography. The traveltimes estimated using the Smith and Sandwell grid had consistently smaller standard deviations compared to those estimated using the GEBCO bathymetry, suggesting that the Smith and Sandwell 30-arcsecond bathymetry product is superior for this application.

\section{Conclusions}

[23] The pressure gauge measurements show that the 2004 and 2006 tsunamis reached the narrow, shallow passages within the eastern Indonesian archipelago. Despite the relatively close proximity of the gauges to the earthquake epicenters and to one another, the tsunami signals seen in the pressure data (Figure 2) have widely varying features, suggesting the importance of local topography in directing the waves. Results from the wavelet analysis also indicate that topography as well as the characteristics of the tsunami source influence how wave energy travels through the passages. High temporal sampling (sampling interval < $1 \mathrm{~min}$ ) of tide gauges and other instruments designed to measure tsunami signals is vital for capturing high-frequency energy. Observations from this study allowed us to gain insight into the traveltime and wave height characteristics of tsunamis in a region where models do not resolve the energy pathways well and few tide gauge measurements were available to verify their results.

[24] The ray tracing model confirmed that details of the bathymetry are important for tsunami propagation through the archipelago. However, because the model neglected reflection, diffraction, and nonlinear interactions, it only accurately predicted traveltimes to stations that were more exposed to the tsunami source regions. This simple, fast ray tracing model was shown to produce similar traveltime estimates to the more complete WC/ATWC tsunami model, and thus could be useful as a "first guess" if computational power and time are limited and if topographical reflection is not thought to be an important factor.

[25] The thousands of islands, passages, and topographical features that make up Indonesia attenuate tsunami signals through reflection and refraction. To improve modeling and prediction efforts, a higher-resolution knowledge of regional bathymetry is necessary.

[26] Acknowledgments. Funding for this work was provided by NASA-JPL contract 1224031 and NSF grant OCE-0220382.

\section{References}

Baba, T., K. Hirata, and Y. Kaneda (2004), Tsunami magnitudes determined from ocean-bottom pressure gauge data around Japan, Geophys. Res. Lett., 31, L08303, doi:10.1029/2003GL019397.

Chong, J., J. Sprintall, S. Hautala, W. Morawitz, N. Bray, and W. Pandoe (2000), Shallow throughflow variability in the outflow straits of Indonesia, Geophys. Res. Lett., 27(1), 125-128.
Fine, I. V., A. B. Rabinovich, and R. E. Thomson (2005), The dual source region for the 2004 Sumatra tsunami, Geophys. Res. Lett., 32, L16602, doi:10.1029/2005GL023521.

Fujii, Y., and K. Satake (2006), Source of the July 2006 West Java tsunami estimated from tide gauge records, Geophys. Res. Lett., 33, L24317, doi:10.1029/2006GL028049.

Gower, J. (2005), Jason 1 detects the 26 December 2004 tsunami, Eos Trans. $A G U, 86(4), 37-38$.

Hayashi, Y. (2008), Extracting the 2004 Indian Ocean tsunami signals from sea surface height data observed by satellite altimetry, J. Geophys. Res., 113, C01001, doi:10.1029/2007JC004177.

Kowalik, Z., W. Knight, T. Logan, and P. Whitmore (2005), Numerical modeling of the global tsunami: Indonesia tsunami of 26 December 2004, Sci. Tsunami Hazards, 23(1), 40-56.

Lavigne, F., C. Gomez, M. Giffo, P. Wassmer, C. Hoebreck, D. Mardiatno, J. Prioyono, and R. Paris (2007), Field observations of the 17 July 2006 tsunami in Java, Nat. Hazards Earth Syst. Sci., 7, 177-183.

Lay, T., et al. (2005), The great Sumatra-Andaman earthquake of 26 December 2004, Science, 308(5725), 1127-1133.

Marks, K. M., and W. H. F. Smith (2006), An evaluation of publicly available global bathymetry grids, Mar. Geophys. Res., 27(1), 19-34, doi:10.1007/s11001-005-2095-4.

Merrifield, M., et al. (2005), Tide gauge observations of the Indian Ocean tsunami, December 26, 2004, Geophys. Res. Lett., 32, L09603, doi:10.1029/2005GL022610.

Molcard, R., M. Fieux, and F. Syamsudin (2001), The throughflow within Ombai Strait, Deep Sea Res., Part I, 48(5), 1237-1253.

Nagarajan, B., I. Suresh, D. Sundar, R. Sharma, A. Lal, S. Neetu, S. Shenoi, S. Shetye, and D. Shankar (2006), The great tsunami of 26 December 2004: A description based on tide-gauge data from the Indian subcontinent and surrounding areas, Earth Planets Space, 58, 211-215.

Neetu, S., I. Suresh, R. Shankar, D. Shankar, S. Shenoi, S. Shetye, D. Sundar, and B. Nagarajan (2005), Comment on "The great Sumatra-Andaman earthquake of 26 December 2004", Science, 310(5753), doi:10.1126/ science. 1118950 .

Pawlowicz, R., B. Beardsley, and S. Lentz (2002), Classical tidal harmonic analysis including error estimates in MATLAB using T TIDE, Comput. Geosci., 28, 929-937.

Potemra, J. T., J. Sprintall, S. L. Hautala, and W. Pandoe (2003), Observed estimates of convergence in the Savu Sea, Indonesia, J. Geophys. Res. 108(C1), 3001, doi:10.1029/2002JC001507.

Rabinovich, A. B., and R. E. Thomson (2007), The 26 December 2004 Sumatra tsunami: Analysis of tide gauge data from the World Ocean: Part 1. Indian Ocean and South Africa, Pure Appl. Geophys., 164(2-3), 261-308, doi:10.1007/s00024-006-0164-5.

Satake, K. (1988), Effects of bathymetry on tsunami propagation: Application of ray tracing to tsunamis, Pure Appl. Geophys., 126(1), 27-36.

Smith, W. H. F., and D. T. Sandwell (1997), Global sea floor topography from satellite altimetry and ship depth soundings, Science, 277(5334), $1956-1962$

Smith, W. H., R. Scharroo, V. V. Titov, D. Arcas, and B. K. Arbic (2005), Satellite altimeters measure tsunami, Oceanography, 18(2), 11-13.

Sprintall, J., et al. (2004), INSTANT: A new international array to measure the Indonesian Throughflow, Eos Trans. $A G U$, 85(39), 369-376.

Stein, S., and E. Okal (2005), Speed and size of the Sumatra earthquake, Nature, 434(7033), 581-582.

Thompson, R. (1983), Low-pass filters to suppress inertial and tidal frequencies, J. Phys. Oceanogr., 13(6), 1077-1083.

Torrence, C., and G. P. Compo (1998), A practical guide to wavelet analysis, Bull. Am. Meteorol. Soc., 79(1), 61-78.

Van Dorn, W. G. (1984), Some tsunami characteristics deducible from tide records, J. Phys. Oceanogr., 14(2), 353-363.

K. Drushka, Scripps Institution of Oceanography, University of California, San Diego, La Jolla, CA 92093-0230, USA. (kdrushka@ucsd. edu)

S. T. Gille and J. Sprintall, University of California, San Diego, 9500 Gilman Drive, La Jolla, CA 92093-0230, USA.

W. S. Pranowo, Alfred Wegener Institute for Polar and Marine Research, Computing and Data Center, Room E-5010, Am Handelshafen 12, Bremerhaven, D-27570, Germany. 